\title{
4. ALGUNAS REFLEXIONES FINALES
}

En el edificio de esta historia hemos empleado materiales tan sólidos como nos ha sido posible conseguir, a la vez que procurando neutralizar parejamente así nuestras simpatías como nuestros resquemores. Lo que sigue, en cambio, es totalmente subjetivo y basado en la cruda apreciación personal, tantas veces sujeta a equivocaciones. El ocasional lector debe encontrarse alerta y prevenido. No puede ni debe, por lo tanto, considerar a estas páginas como a un capítulo más de esta Historia, sino sencillamente como su culminación, en el sentido astronómico que se da al término. Así, no resta otra alternativa que bajar. Pero antes de abandonar definitivamente el otero, el espíritu -como el de quien va a descender de una alta cumbre- desea recompensarse de sus muchos trabajos con una postrera mirada en torno, capaz de cnriquecerlo mientras viva. Ese anhelo espiritual ex plica y justifica, creo, la redacción de estas líneas.

Ya en la etapa final de nuestro trabajo, juzgamos que ha de ser positivo condensar una valoración crítica de los logros alcanzados por los arqueólogos que, a lo largo de casi once décadas han iniciado, jerarquizado después y finalmente profesionalizado a la investigación arqueológica en nuestra tierra. Evaluar cs, ciertamente, tarea tan difícil como ingrata. Sin embargo, historiar una ciencia no puede tener otra finalidad en vista que no sea la de llegar a una evaluación final. Y en el caso presente dicha tarca ha de ser doblemente dificultosa, ya que aspiramos no solamente a ponderar los adelantos científicos verificados, sino también, y en difcrentes dimensiones, a los cultores mismos, que fueron los ejecutores de aquéllos. En otros términos, en la medición de los nuevos conocimientos que cada uno aportara, no quisiéramos perder la dimensión que corresponde al lombre. Interesará, en primer término, dibujar una imagen caracterizante del "arqueólogo argentino tipo". Tal esfuerzo, lo sabemos bien, está de antemano condenado al malogro, pero aún así, vale la pena intentarlo. Existe, por lo menos, un barniz particular para cada una de las profesiones, un cúmulo de procedimientos, actitudes y comportamientos que son específicos de cada actividad humana. Cada una de éstas implica un riesgo profesional, mayor o menor, pero siempre presente y, si se quiere, hasta una forma de actuar, de hablar y de escribir, que le son propias. Los riesgos emparejan el comportarnicnto. Los arqueólogos no escapan a estas reglas o premisas, debiendo por lo tanto tener su propia etología. En páginas precedentes hemos tenido oportunidad de seguirlos desde sus iniciales tentativas hasta sus logros casi espectaculares en tiempos menos remotos y más próximos a no- 
sotros. Tenemos la enorme ventaja de haberlos conocido a todos y a cada uno de ellos: son, en total, un centenar y medio de arqueólogos activos que registran bibliografía, dispersos sobre un segmento temporal que abarca casi once décadas: breve trayecto para una ciencia de desarrollo igualmente breve. De manera que se juzga factible y constructivo - por lo aleccionador que podría resultar-, obtencr un valor medio de sus características, de sus falencias, de sus cualidades positivas, y de sus méritos tanto como de sus fracasos.

La tarea se presenta ardua, porque de inmediato se piensa en la forma de poder conciliar y nivelar a pareja cota a dos personalidades como las de Boman y Ambrosetti - por ejemplo-, nórdico el uno, meridional el otro, con las diferencias temperamentales que aún tan elemental adscripción étnica pueda entrañar desde el principio. Para más hijo de los halagos de la for tuna el segundo; mientras que el otro sólo pudo bajar a la tierra por cariñosa mediación y suscripción de sus amigos; campechano, abierto, siempre franco y cordial y sonriente Ambrosetti; de carácter tormentoso Boman, y con la adustez del hombre que constantemente ha tenido que enfrentarse con la cara no risueña de la vida. Y, paradójicamente, a pesar de transitar tan diferentes senderos, a pesar de las disimilitudes y contrastes, queriendo hacer ambos las mismas cosas, obtener los mismos logros y alcanzar parejas realizaciones. Pero no son Boman y Ambrosetti los únicos exponentes de estas vidas paralelas y disimiles que caracterízan o han caracterizado a diferentes protagonistas de algunas etapas de nuestra arqueología. Pienso en Outes, silencioso y reconcentrado, igualmente tormentoso, febrilmente dedicado a la exploración de su microcosmos protector, y lo contrapongo a Zeballos, sonriente y bromista en sus reuniones del $\mathrm{Clu} b$ del Progreso, siempre galano y florido y amante de las compañías gratas. Ambos provenían de familias argentinas que hundían su ancestro en estratos raigales de nuestra historia, poseedoras de recursos y de fortuna; pero uno gozó permanentemente de la posesión de una salud de hierro, que posibilitó sus continuadas audacias, y el otro, Outes, el verdaderamente nacido para explorador de las tierras distantes, para el enfrentamiento con los peligros, con las privaciones sin fin, con los soles calcinantes y con las nieves traidoras, debió resignarse a explorar nada más que el perímetro de su vasta biblioteca, único entorno donde jamás ha de haberse sentido totalmente solo, y abrevadero fresco y nunca ciego para él, del que hizo su verdadero ámbito ecológico y en el que a prendió a sobrellevar su tragedia (originada en una enfermedad crónica).

Podría menudearse la cita de contrastcs tan evidentes y marcados, pero no vale la pena; pues, a pesar del aparente abismo abierto frente a la perso nalidad de cada uno de ellos, existen rasgos que posibilitan la unificación de ciertos aspectos, delimitando constantes psicológicas y temperamentales. Hemos de ocuparnos, por supuesto, sólo de los arqueólogos clásicos o heroicos, tocando a algún futuro historiador de la ciencia - con seguridad, ya en la centuria próxima-, intentar una scmblanza de los cultores recien- 
tes de la arqueología, contemporáneos nuestros. En primer lugar, el individualismo ha sido enfermedad endémica largamente padecida por el arqueólogo argentino, junto a una afectada propensión al logro de una erudición casi absoluta, que en algunos casos ha derivado a un franco cientificismo. Marcada tendencia al exclusivismo en el tratamiento de las cosas y de los problemas - de ese tema ya me vengo ocupando yo, diría inhibitoriamen: te Outes-,y, aunque en menor grado, cierta inclinación al narcisismo científico. Otras propensiones hasta podrían calificarse de feminoides, y su presencia sólo puede ser satisfactoriamente explicada por el hecho de que el arqueólogo debe actuar en un plano que es frontero a la ciencia y al arte, y a que es un permanente (e imconsciente) coleccionista (de objetos, de conocimientos). En varios se ha dado la siguiente contraposición: desdibujamiento de los procedimientos fácticos ("cómo", "cómo hacer"), contrapuesto a un fácil desbordamiento en los planteos teóricos o explicativos, cuyos resortes manejó a la perfección y lo han convertido, muchas veces, en un erudito auténtico. Entre los rasgos positivos, destacamos: laboriosidad casi rayana en la manía, y una capacidad casi mágica para la ejecución de empresas, trabajos y proyectos careciendo aún de recursos mínimos y verificándolos, no obstante, sin comprometer los resultados. Finalmente, un talento manifiesto en todos los cultores, y hasta cierta heroicidad y persistencia de Sísifo en la ejecución de una tarea que fatalmente está condenada a ser erosionada o modificada por el avance inimterrumpido de los conocimientos y de las renovaciones metodológicas.

Grandes solitarios han sido varios de nuestros más destacados arqueólogos; si a la vez románticos y sensitivos, como Debenedetti, esos solitarios han dejado, no obstante, numerosos admiradores a distancia. Pero, en líneas generales, ninguno de esos grandes cultores del personalismo ha dejado discípulos, a lo sumo deslumbrados admiradores o emuladores, si no simples herederos. En la etapa universitaria de nuestra arqueología, pareciera no haberse llegado a generar una verdadera universitas magistrorum et scholarium. Si en un principio se habrían formado tales discípulos presuntos, se los ha visto más tarde tomar por senderos bien diferentes a los

Figura 2: Graficación porcentualizada que muestra la evolución de las principales corrientes del pensamiento arqueológico argentio a través del tiempo, entre 1865 y 1975 . La columna extre. ma de la derecha ("totales"), expresa el número total de publicaciones correspondientes a un año, lapso en que las distintas tendencias encuentran su expresión materializada.

Se pucde apreciar lo antiguas que son las corrientes "naturalista" y "etnohistórica", la primera algo más que la segunda, pero destinada a desaparecer antes. La corriente "etnohistórica" subsiste débilmente en nuestros días.

El panorama arqueológico argentino es hoy gobernador por las corrientes "humanista" y de la "Nueva Arqueología", teniendo esta última ou antecedente inmediato -en nuestro medio-, en los "prolegómenos", corriente ésta que filosóficamente no es posible reducir ni a la metodología "naturalista" ni a la "etnohistórica".

Finalmente, en los "neutros" se han encolumnado las obras que no pueden derivarse a his demás corrientes. Difícilmente constituyan un movimiento definido, porque en esa columna han sido colocados los trabajos de autores cuyos antecedentes no autorizan una asignación segura, generalmente por haber producido una sóla publicación, o haberse dedicado posteriormente a otra6 ta. reas. 


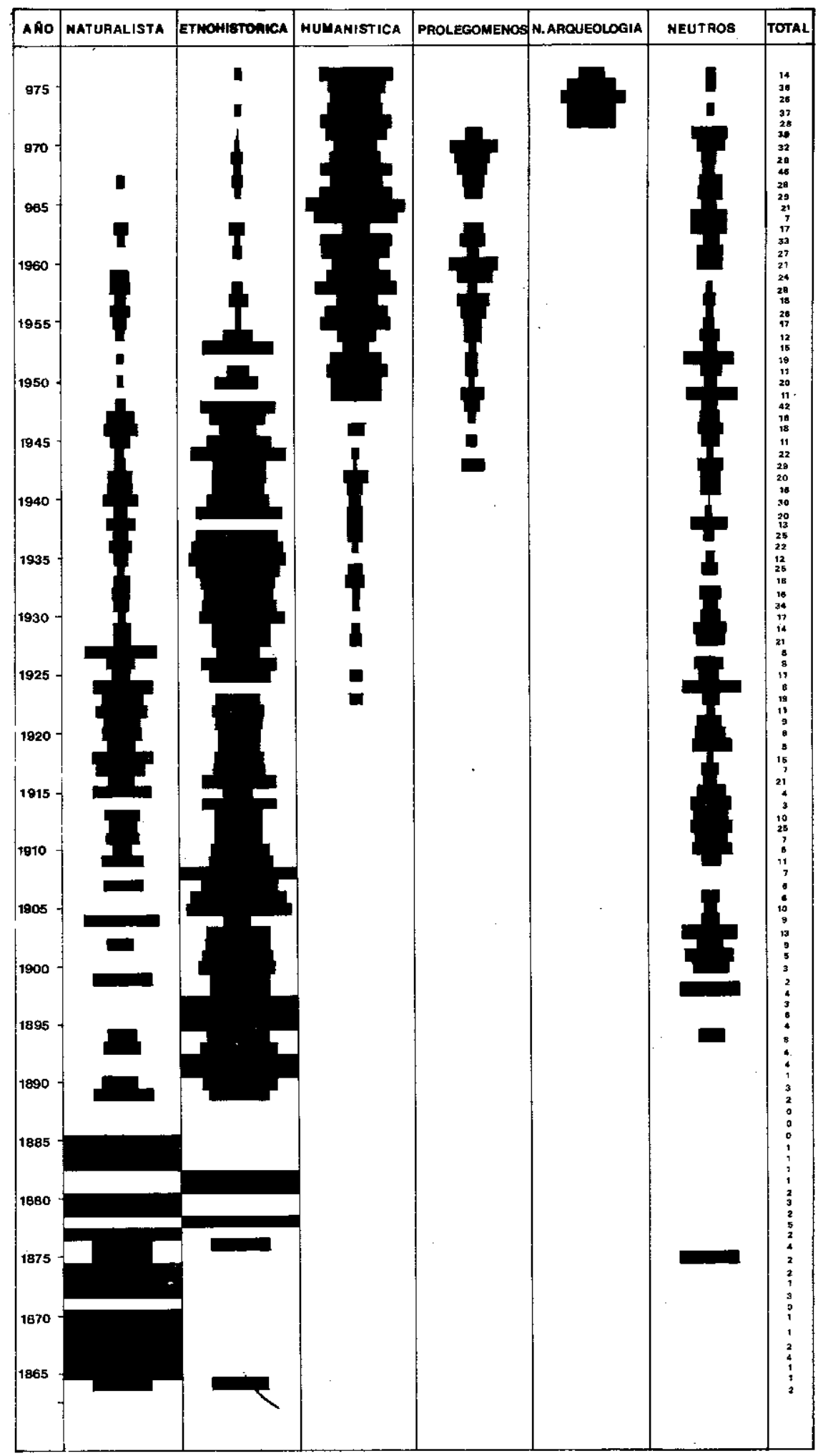


inicialmente apuntados, y aún haciendo franca deserción del menester arqueológico. La generación de discípulos pareciera rehuír aquellos lugares donde no reine el buen humor, y por lo general el arqueólogo nuestro ha sido un malhumorado, un irónico o aún un colérico; en casos más benignos, un reconcentrado. Muchas vocaciones arqueológicas han despertado espontánea o casi espontáneamente en nuestro medio, queriendo significar con esto que lo han hecho careciendo del impulso irradiante de un ejemplo precedente, claro, luminoso y orientador, emanante de un maestro. Algo así como un faro, sólidamente aferrado a la roca del acantilado. Faro cuya luz es tal vez intermitente, y a la que no se exije que sea muy intensa, pero sí que sea segura en la plenitud de las tormentas. No parecieran ser muchas las condiciones requeridas para ser maestro de maestros futuros. Lo dicho, está de más aclararlo, guarda exclusivamente relación con los logros científicos y los métodos a seguir para alcanzarlos, quedando los aspectos morales involucrados muy por encima de nuestras apreciaciones. Evidentemente, una de tales condiciones o requisitos para ser conductor moral dc otros intelectuales, es la autoridad suficiente. Entonces se piensa de inmediato en la vastedad de los conocimientos de Imbelloni -cs un ejemplo-, en la inconmensurable erudición de sus trabajos, en su vigorosa seriedad, exhudantes de autoridad y también de suficiencia. Pero Imbelloni, fundador de lo que en su época se llamó la "escuela argentina de antropología" o, simplemente, "la escuela de Buenos Aires", colmó sus aspiraciones integrando en ella a muy distinguidos colaboradores.

También Ameghino ha tenido extraordinariamente desarrollado el don maravilloso, casi milagroso, de generar discípulos y continuadores. Pero él fué un profeta, y sus continuadores, apóstoles. Y la palabra del maestro, "santa" y virtuosa, obedecida al pie de la letra, y sus esquemas de trabajo, sus sistemas y principios, defendidos contra viento y marea, no con la fidelidad cariñosa y reverente del discípulo, sino con tozudez y empecinamiento religioso, a pesar de su falsía cada vez más evidente. Así, las posibilidades de formación de una escuela arqueológica ameghiniana fueron deteriorándose progresivamente hasta su desintegración total hacia 1950.

Sencillez y bondad, condiciones no nacidas del intelecto, pero moldeadoreas de muchos de los frutos que pueden derivarse de los desarrollos de

* En uno de los numerosos intercambios de ideas que tuvieron lugar entre el autor y el director de la publicación, durante la revisión del texto destinado a su publicación, éste preguntó al autor cuáles serían las causas de esas actitudes, y si los avatares político - institucionales no habrían influido en ello. La respuesta fue, que la historia de la arqueología correspondiente a los últimos cincuenta años ha estado provista -como toda actividad humana- de una trama política a la que cabe considerar aceptable y lógica. Pero también la orientación -y no ya sólo el desenvolvimiento-de esos estudios ha estado influido por la política, en forma que debe considerarse menos aceptable. Intencionalmente se ha soslayado este aspecto, para cuyo análisis no existe aún perspectiva suficientc. (N. del D.) 
éste, fueron cualidades poseídas casi en igual grado por Ameghino, Ambrosetti y Menghin. Esa sencillez y bondad quizá puedan explicar la relativa popularidad alcanzadas por las empresas y estudios encarados por esa trilogía, o la comprensión y el cariño de que disfrutaron en ambientes mucho más vastos que los estrietamente académicos, y en los que su recuerdo no sólo no ha muerto, sino que permanece fresco todavía.

Por lo demás, sería injusto que las críticas apuntaran exclusivamente hacia los posibles maestros. Igualmente han escaseado recipiendarios dis puestos, es decir, discentes aptos, para lo cual se necesita igualmente tener no sólo la vocación, sino también la disposición y la estructura de tal, con todo lo que ella entraña de vocación de servicio y aún de servidumbre y grandeza (porque hay, efectivamente, una vocación de grandeza en todas las grandes servidumbres).

Tal vez sea esta carencia de continuidad filética la quc pueda explicar el comportamiento de las generaciones cuyos individuos integrantes han vertido duros conceptos al juzgar a sus predecesores, no sólo los precursores heroicos, sino también a los que los sucedieron. Tales manifestaciones de divorcio están escritas y tenemos por lo tanto no sólo el derecho, sino también, como historiadores, la obligación ineludible de tomarlas en cuenta y de analizarlas en esta historia. Se ha dicho que tales críticas han sido vertidas en el deseo de cortar todo vínculo con el pasado, o mejor con la carga negativa que esconde todo pasado; pero debieran, más bien, adscribirse a la inseguridad, y aún al temor, pero sobre todo a la desesperanza de no poder hallar la forma de soldar los logros provenientes de las nuevas modalidades de la arqueología y sus miras, con los que caracterizaran a la arqueología de antaño. Semejante negación es un planteo típico de nuestro medio, en el que las divisiones pueden llegar a extremos inauditos. Allí donde se niegue validez y contenido esencial a ciertos tramos de la Historia, no debc extrañar el silenciamiento o menoscabo de ciertas etapas de la arqueología, o por lo menos, de la arqueología realizada por determinados arqueólogos. Lo concreto, sin embargo, es que han sido los precursores y sus continuadores los que hasta ahora han podido dar cima en plenitud a la aspiración que debe suponerse fundamental en todo arqueólogo: dar eco al silencio.

Los recursos metodológicos poseídos por los arqueólogos contemporáneos, que en apariencia autorizarían a descreer de buena parte de lo anteriormente realizado, no han traído consigo aparejados resultados que puedan reputarse deslumbrantes. No por falencia eonceptual o metodológica, sino sencillamente, por desaplicación o inaplicación. Lo cierto es que no hemos descubierto -por ejemplo- nuevas culturas mediante el empleo del avión y de la fotografía aérea, cuando más hicimos de ambos aplicaciones concurrentes. Tampoco la resistividad eléctrica nos ha auxiliado mucho en el descubrimiento de viejas y reeónditas tumbas. Los resultados emergentes del empleo de la palinología, del método del flúor, de la sedimentolo- 
gía y de la medición isotópica, oportunamente presentados como panaceas a nuestras supuestas deficiencias, no han producido aquí ni vuelcos ni reinterpretaciones totales. Por lo menos, no en la mcdida en que pudiera esperarse. La aplicación de algunos métodos no pasó de la amenaza vana; y la calota del "diprothomo", el "anthropodus" o el toxodón flechado pudieron contemplar, desde las empolvadas vitrinas en que yacían, la decadencia progresiva y la obsolescencia final de alguno de ellos. Si cl olvido no constituye una forma aún más grave de la derrota, ciertamente no fueron ellos los derrotados. En cambio, es notorio que ciertas reconstrucciones culturales magistralmente realizadas, fueron hechas en base a materiales documentales obtenidos en la década del ' 20 . Así pues, entre las hebras constituyentes del haz de la personalidad arqueológica, incluyamos también el entusiasmo desbordante, aunque pasajero y superficial, por las nuevas técnicas auxiliares, de las que no siempre se ha hecho un uso adecuado, y sí muchas veces ingenuo. ( $\mathrm{i} \mathrm{Oh}$, los cuadros cronológicos de las glaciaciones cuaternarias, o la significación cronológico-cultural proporcionada por las terrazas marinas de una costa que el mar devora desde hace milenios, o que la isostasia maneja a su arbitrio; o el de las terrazas fluviales, cuyos incidentes genéticos ni los mismos especialistas de la geología dominan todavía! ¿Y las lluvias de ceniza, la tefrocronología, los "estratos negros", el "optimum climaticum"? ¿Qué diferencia puede haber, en el fondo, entre todo esto y cicrtas fantasías ameghinianas, frente a las cuales sonreímos hoy con lástima o con desprecio?)

Esta propensión a la crítica -no ya cauterizante, sino decididamente cáustica--, hacia los antiguos cultores, ese afán defenestratorio por los esfuerzos del pasado, perfectamente detectable en algunas de las exégesis que se han efectuado en las últimas décadas, todas ellas iniciadas con un velado o franco reproche, pareciera ser otro de los rasgos definitorios del arqueólogo local. Arrasar con lo ajeno, o ignorarlo, aún antes de comenzar con lo propio. Muchas podrán ser las causas que han obstaculizado el desarrollo de la arqueología doméstica, pero entre ellas no debiera incluirse el accionar metodológico de los viejos arqueólogos. Ninguno de los hallazgos de los últimos decenios sobrepasa en significación a la que en su momento tuvo el descubrimiento de los campos con menhires de Tafí, verificado por Ambrosetti en 1896; o a la asombrosa masa de información emergente -también en su momento- del hallazgo hasta ahora incomparable de restos de fauna extinta asociada a implementos industriales descubiertos y estudiados por Moreno, Hauthal, Roth, Lehmann Nitsche, etc., entre 1895 y 1900 en la "Cueva del Mylodon"; o el de la momia, contenido estratigráfico y arte rupestre nuevos de la caverna de Punta Gualichu, Lago Argentino, producido por Moreno el año 1876. Escasos han de ser los arqueólogos que, también en el transcurso de las últimas décadas, hayan efectuado un descubrimiento de la importancia y envergadura que oportunamente tuviera el verificado por los hermanos Wagner en una región olvidada de las llanuras santiagueñas, desahuciada por la arqueología, dondc 
desenterraron para la ciencia una civilización hasta ese momento ignorada de todos. En número y amplitud geográfica del área prospectada, pocas excavaciones arqueológicas podrán compararse a las de V. Weiscr; en calidad podrán ser igualadas, pero difícilmente superadas. $\mathrm{Y}$ otro tanto podría decirse de la excavación y reconstrucción -única hasta que Cigliano dirigiera la reconstrucción de Tastil-, de las ruinas arqueológicas de Tilcara, llevada a cabo por Casanova a trueque del desgaste de una etapa importante de su vida. Mas ¿para qué abundar?

Tampoco es cierto que hayan trabajado mal, o excavado "a la diable", como maliciosamente se ha escrito; aunque sí es cierto que lo hayan hecho innersos no sólo en sus propias limitaciones personales (a igual que nosotros), sino también en las concernientes a sus respectivas épocas. Pero, aún así, alcanzaron a elaborar un esquema general con el que pudieron ellos trabajar, con el que en parte, por lo menos, trabajan los arqueólogos actuales y con el que aún deberán trabajar quién sabe cuántas generaciones más de arqueólogos, a las que sólo les cabe ensanchar los horizontes como producir una profundización de los conocimientos, reacomodando la sucesión de las culturas, descubriendo lo que aún falte descubrir e investigando aqueLlas áreas que ni los precursores, ni los arqueólogos contemporáneos han podido estudiar. Porque, región que no ha sido fecundada por los esfuerzos resultantes del desbrozamiento preliminar dc los trabajadores de las etapas comprendidas entre 1880 y 1940, es región que permanece aún en blanco, sobre las que poco han logrado las técnicas y los técnicos evolucionados.

También existen defectos nivelatorios, de los que tanto han adolecido los arqueólogos de las etapas intermedias, como los del presente. Aunque la arqueología argentina nace en las llanuras y cobra vigor en las estepas de la región semiárida, la primera crítica que se puede hacer en una visión global y retrospectiva como la presente, es el deslumbramiento que todos hemos experimentado hacia los aspectos emanantes del Noroeste (sector andino de las provincias de Catamarca, La Rioja, Tucumán, Salta y Jujuy), en detrimento y aún con exclusión de las regiones de llanura (Chaco, Pampa, Patagonia y parte de la Tierra del Fuego), no obstante que las culturas del sector andino de nuestro territorio no podían ser más que marginales, apéndices del gran centro andino ubicado más al norte, y que consecuentemente, sólo apendiculares y marginales podían ser nuestros estudios en ellos, supeditados a los adelantos verificados por la investigación en los centros de alta cultura, y por lo tanto subordinados a ellos. Los "desarrollos" o "florecimientos locales" no alcanzan a cubrir esa deficiencia. Se abandonó así un cauce de investigación genuinamente original, que para un país de las características del nuestro, integrado en un ochenta por ciento de llanuras, debió haberse abroquelado preferentemente en el estudio de las culturas del llano, procurando una complementación e inserción en lo andino. Dcbicron haber sido exhondados los profundísimos cauces comenzados a abrir por Amcghino - un explorador dc llanura--, hace ya más de cien 
años, y de allí haber procurado la integración con los Andes (pues la influencia dc los Andes, para qué negarlo, esta siempre presente entre nosotros). Pero, en lugar de eso, nos hemos preocupado en efectuar grandes disquisiciones en torno a "lo andino" y a "lo amazómico", como si el nuestro fucra un territorio o un país andino o del Amazonas, o como si aquellos problcmás nos tocaran de tan cerca, en cambio de no ser más que metástasis que culturalmente sólo en forma ocasional han tenido repercusión en nuestro ámbito físico preponderante, que es la llanura. Nos hemos contentado con explicaciones ingeniosas y de erudición ardua, aunque un tanto alquímicas. Es indudable que algo hemos logrado, por lo menos el convencimiento de que tales influencias han existido, pero mientras tanto ignoramos el desarrollo local de otras áreas culturales, como las de Tierra del Fuego, de la Pampa o del Chaco. Menglin, junto con otros investigadores aún vivientes, no reincidió en el error, $\mathrm{y}$ al exhondar en lo patagónico y en lo pampcano renovó y dio nueva orientación al estudio arqueológico; González, ha hecho vibrar las estructuras de la arqueología nacional -y de la sudamericana-, no bien hincó su piqueta en el montañoso borde noroccidental de las pampas.

Hoy son aquellos países de arqueología bizarra --Venezuela, Ecuador, Perú, Cliile Boreal-, los que han vuelto las miradas y los esfuerzos, con ansias renovadoras, a problemas quc en la Argentina fueran encarados en el comienzo mismo de la investigación arqueológica, desde Ameglino. Los investigadores brasileños, mientras tanto, han demostrado ya que lo original puede también no estar en las proximidades de los grandes centros de cultura, con lo que están dando cuerpo y sólida base al sustrato de una na cionalidad tan compleja desde el punto de vista étnico. Aún hoy, como en el pasado, y como sin duda alguna lo será también en el futuro, la solución de muchos grandes problemas de la prehistoria americana deseansa en el fondo limoso de las pampas y en las regiones geográficas que contactan con ella (Patagonia, Mesopotamia, el Gran Chaco).

Se comprende y aún puede justificarse la vigencia del espejismo andino durante las etapas intermedias de nuestros estudios arqueológicos, no existiendo en nuestra arqueología de entonces desarrollos locales (ecntros de investigación). Con el aumento de éstos, era de esperar una mejor división del trabajo. Igualmente era antes aceptable una limitación a continuar y aún a imitar lo que se hacía en México y en Perú, principalmente por arqueólogos norteamericanos. Pero después, con la aparición de una arqueología de tendencias presuntamente renovadoras, que aspiró a la demolieión de estructuras supucstamente perimidas, resulta inexplicable la perviven cia de las mismas orientaciones. Es decir, no condicc el contenido de la prédica quc cuestionó lo realizado, que se tituló renovadora tanto en métodos como en táctica, y que sin embargo se mantuvo apegada a viejos procedimientos y se empcñó en aplicarlos al cuerpo de lo que para ella ha sido un crónico cspejismo. La focalización cxagerada, por momentos casi ex- 
clusiva, que la investigación arqueológica argentina ha hecho en el llamado Noroeste agroalfarero, tal vez haya sido la rémora más eficaz para el logro de su verdadero destino.

Una verdadera estrategia ya hubiera desmenuzado el enígma agazapado en las tierras llanas y avizorado una explicación para el singular comportamiento cultural en las llanuras. Hubiera dado, con ello, una base de entendimiento a la que todavía aspira con derechos el ser nacional, en último análisis producto resultante de la conjugación de un sustrato telúrico (en el que sin duda tuvo un importante papel lo andino arcaico), a quien el destino impuso Ia impactación por fuerzas no siempre destructivas procedentes del Este.

Doy por finalizada esta historia, hallándome en tierra neuquina, al pie de mis excavaciones. Se siente la presencia viva de nuestros antecesores, tanto las poblaciones aborígenes como los investigadores que iniciaron su estudio. Ha sido honesto el esfuerzo por no olvidar a nada, ni a nadie. Tengo el convencimiento -y así espero habérselo transmitido al lector- de haber tratado en estas páginas acerca de una arqueología que conscientemente ha entrado ya en una etapa de superación de su historia; pero que, como el Cóndor a que aludiera Félix Outes, quiso distinguirse siempre por el vuelo raudo y el planear sereno.

Chenque Haichol - Buenos Aires, Principios de 1979. 

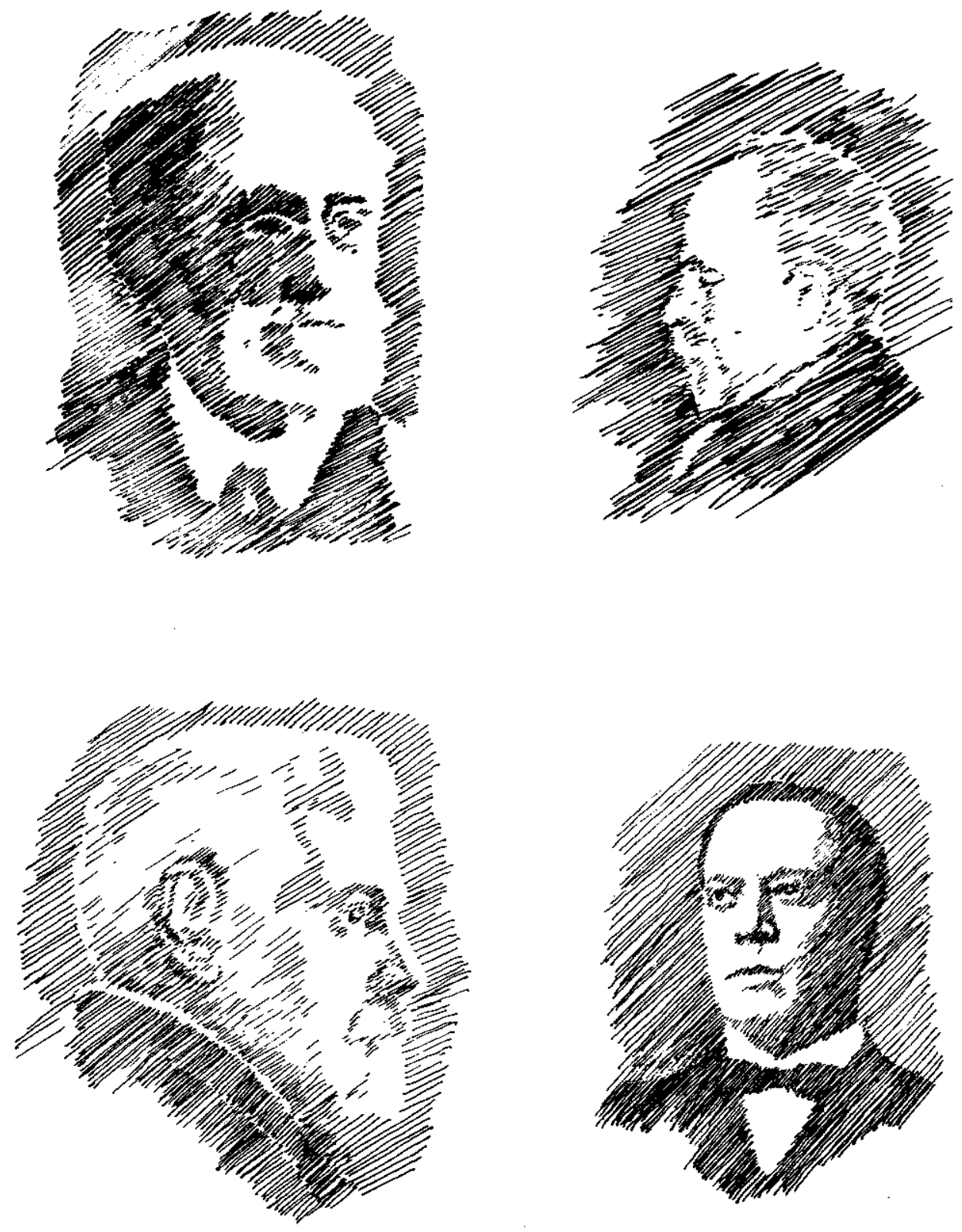

(Dibujo Julio O.Ferrari)

Viñeta:

S. Lafone Quevedo, F. Ameghino (arriba); J.B. Ambrosetti, S. Debenedetti (abajo). 